\title{
The New Zealand obese mouse model of obesity insulin resistance and poor breeding performance: evaluation of ovarian structure and function
}

\author{
Simone Radavelli-Bagatini ${ }^{1}$, Amy R Blair, Joseph Proietto, Poli Mara Spritzer ${ }^{1,2}$ \\ and Sofianos Andrikopoulos \\ Department of Medicine (Austin Health/Northern Health), Heidelberg Repatriation Hospital, The University of Melbourne, 300 Waterdale Road, Heidelberg \\ Heights, Melbourne, Victoria 3081, Australia \\ ${ }^{1}$ Department of Physiology, Universidade Federal do Rio Grande do Sul, UFRGS, Porto Alegre, Rio Grande do Sul 90035-003, Brazil \\ ${ }^{2}$ Gynecological Endocrinology Unit, Division of Endocrinology, Hospital de Clínicas de Porto Alegre, HCPA, Porto Alegre, Rio Grande do Sul 90035-003, Brazil \\ (Correspondence should be addressed to S Andrikopoulos; Email: sof@unimelb.edu.au)
}

\begin{abstract}
Infertility, associated with oligo/anovulation, increased ovarian volume, numerous follicular cysts, and metabolic disturbances such as obesity and insulin resistance (IR) are characteristics common to polycystic ovary syndrome (PCOS), the most common endocrine disorder in women of reproductive age. Here, we show that New Zealand obese (NZO) mice display similar metabolic characteristics such as obesity, leptin insensitivity, glucose intolerance, and IR. Importantly, NZO mice are poor breeders; however, the mechanism for this has not been investigated. The aim of this study was to assess the ovarian structure/morphology and sex hormone levels in female NZO and lean C57BL/6J control mice. Twenty-five NZO and twenty female control mice were studied at three different ages (young, adult, and aged). The animals were weighed, an insulin tolerance test was carried out, and blood was collected for measurement of hormone levels. The ovaries were removed for histological
\end{abstract}

analysis. As expected, NZO mice presented higher body weights $(P=0.001)$, increased basal plasma glucose $(P=0 \cdot 007)$, and insulin levels $(P=0.001)$ as well as IR, compared with control mice. NZO mice showed an increased ovarian volume, reduced numbers of corpora lutea, and higher total follicle numbers $(P=0 \cdot 0001)$. The number of primordial follicles increased $(P=0 \cdot 02)$ at the young stage, as well as the amount of atretic follicles $(P=0 \cdot 03)$, in NZO compared with control mice. NZO mice also displayed reduced plasma $\mathrm{LH}$ and increased estradiol levels. In conclusion, NZO mice show a poor breeding performance due to decreased ovulation, increased number of primordial and atretic follicles, and ovarian size. Given that NZO mice are obese, hyperinsulinemic and insulin resistant, they are suitable for investigating pathophysiological mechanisms linking metabolic alterations with reproductive defects.

Journal of Endocrinology (2011) 209, 307-315

\section{Introduction}

Infertility associated with oligo/anovulation, changes in ovarian structure and function, and metabolic disturbances such as obesity and insulin resistance (IR) are characteristics common to polycystic ovary syndrome (PCOS), affecting $5-10 \%$ of the female population (Asuncion et al. 2000, Lobo \& Carmina 2000, Norman 2002, Azziz et al. 2004, Norman et al. 2004, Ehrmann 2005). In its classic form, it is characterized by oligo/anovulation and hyperandrogenemia. The etiology of PCOS is unclear but evidence suggests that it is a genetically determined ovarian disorder in which excessive androgen production early in life may provide a hormonal insult that leads to PCOS in adulthood (Barnes et al. 1994, Crosignani \& Nicolosi 2001, Franks et al. 2006). The characteristic morphological feature of polycystic ovaries is the accumulation of numerous small antral follicles in the range of $2-8 \mathrm{~mm}$ in diameter (Franks et al. 2000), due to an apparent failure to select a dominant follicle, resulting in an abnormal ovarian endocrine environment (Webber et al. 2003).

PCOS is also closely associated with metabolic disturbances, most commonly obesity-associated IR (Spritzer et al. 2001, Toscani et al. 2007) and compensatory hyperinsulinemia (Dunaif 1997, Ehrmann 2005). It is reasonable to suggest that the elevated androgen levels characteristic of PCOS contribute to the increased amount of adipose tissue deposition, particularly in the abdominal region in these women (Barber et al. 2006). These metabolic abnormalities have implications both on reproductive function and for long-term health. Weight loss and treatment with insulin-sensitizing drugs (e.g. metformin) can increase the rate of reproduction (Zain \& Norman 2008, Leeman \& Acharya 2009). 
The availability of a suitable animal model would provide a useful means to study the etiology of infertility associated with changes in ovarian structure and function, such as in PCOS. Owing to the heterogeneity of PCOS, it is difficult to create a single-animal model that expresses the main PCOS characteristics. Common models of PCOS include female rats exposed to testosterone (Beloosesky et al. 2004) or the aromatase inhibitor letrozole (Kafali et al. 2004, Manneras et al. 2007) to cause cystic follicles and endocrine features similar to human PCOS. However, these induced models do not develop many of the metabolic disturbances (e.g. increased plasma testosterone, abdominal fat deposition, and IR) that may be important to the disease process. Perhaps, a better model is the prenatally androgenized rhesus monkey that displays hyperandrogenism, anovulation, polyfollicular and enlarged ovaries and metabolic disturbances including increased adiposity and insulin insensitivity (Abbott et al. $1998,2005,2008$ ). Of course, the usefulness of this primate model is hampered by the specialist vivarium and cost required for such studies.

The New Zealand obese (NZO) mouse is a polygenic model of obesity, IR and hyperinsulinemia (Veroni et al. 1991, Fam et al. 2007). One of the earliest described characteristics of the NZO mouse is poor breeding performance such that there was a real possibility that this line may be lost. Of 161 female NZO mice mated at 8 weeks, $94 \%$ produced litters and $80 \%$ weaned their first litter (Bielschowsky \& Bielschowsky 1956). However, only $32 \%$ of NZO females had their second litter within 19-25 days of their first, which is strikingly lower than the control mice, with $90 \%$ having their second litter within the same interval (Bielschowsky \& Bielschowsky 1956). In light of the obesity, IR, and poor breeding performance, we were interested in investigating the NZO mouse further to understand the cause of the poor breeding performance. We hypothesize that the poor breeding performance of the NZO mouse is due to altered ovarian structure and function. The aim of this study was to characterize the reproductive hormone levels and ovarian structure in young, adult and aged female NZO and C57BL/6J control mice.

\section{Materials and Methods}

\section{Animals}

$\mathrm{NZO}$ and C57BL/6J female mice were purchased at 8 weeks of age from the Walter and Eliza Hall Institute of Medical Research (Kew, VIC, Australia). Pups were raised with their biological mother until weaning (21 days of age) and then housed 2-4 per cage under controlled conditions (temperature of $21^{\circ} \mathrm{C}$, humidity of $60 \%$, and kept on an artificial lighting on a $12 \mathrm{~h}$ light: $12 \mathrm{~h}$ darkness photoperiod), and allowed free access to commercial rodent chow (3\% fat, $20 \%$ protein, and 77\% carbohydrate; Ridley Agri Products, Pakenham, VIC, Australia) and tap water. The study was approved by Austin Health Animal Ethics Committee and all the experiments were in accordance with the guidelines for the care and use of laboratory animals specified by this Committee.

\section{Study procedure}

Female NZO and C57BL/6J control mice were studied at 12,24 , and 43 weeks of age, and referred to as young, adult, and aged (Frick 2009). The following procedures were conducted.

Intraperitoneal insulin tolerance test The insulin tolerance test was performed as previously described (Andrikopoulos et al. 2000b). Briefly, mice were injected i.p. with $1.0 \mathrm{IU} / \mathrm{kg} \mathrm{BW}$ of insulin (Actrapid MC; Novo, Bagsvaerd, Denmark) and blood samples ( $~ 5 \mu \mathrm{l})$ were drawn from the tail vein for the measurement of blood glucose levels on a hand-held Medisense Optium glucometer at 0, 15, 30, 45 , and $60 \mathrm{~min}$ after the insulin injection.

Hormone assessments Animals were anesthetized with sodium pentobarbital and blood samples were obtained by cardiac puncture after a 6-h fast to assess plasma glucose, insulin, testosterone, estradiol $\left(\mathrm{E}_{2}\right)$, and $\mathrm{LH}$ concentrations. Plasma samples were stored at $-80{ }^{\circ} \mathrm{C}$ on the day of extraction and then submitted for RIA. All samples were assayed in duplicate at the Monash Institute of Medical Research (MIMR), Monash University (Clayton, VIC, Australia). Intra-assay coefficient of variation (CV) was $8 \cdot 2$, $8 \cdot 4$, and $12 \cdot 2 \%$ for testosterone, $\mathrm{E}_{2}$, and LH respectively. As these hormonal measures were done in one assay, there is no inter-assay variation. Plasma glucose levels were measured using a GM7 Analox Glucose Analyzer (Helena Laboratories, Mount Waverley, VIC. Australia), with the linear range being $0-50 \mathrm{mM}$ when using $5 \mu \mathrm{l}$ of sample and intra-assay CV of $1 \cdot 4 \%$. Plasma insulin concentrations were determined by a commercially available RIA specific for rat insulin (Millipore, St Charles, MO, USA) with a range of $0 \cdot 1-10 \mathrm{ng} / \mathrm{ml}$, intraassay $\mathrm{CV}$ of $2 \cdot 9 \%$ and interassay $\mathrm{CV}$ of $9 \cdot 0 \%$.

Histology Ovaries were removed, fixed in Bouin's fixative, dehydrated in ethanol, and embedded in paraffin. Serial sections of $4 \mu \mathrm{m}$ thickness were stained with hematoxylineosin and then evaluated for follicle stages, as described before (Pedersen \& Peters 1968), using an Olympus BX50 Phase Pol Darkfield Microscope and MCID Core Software. At least four sections from each ovary were analyzed and the data presented as the mean of the results acquired from right and left ovaries.

The area of the ovary was determined using the virtual microscope and follicles were also measured and counted. The ovarian follicles and corpora lutea (CL) at different stages of development and regression, and the theca and granulosa cell layer were analyzed in detail.

The follicles were counted and classified as healthy or atretic (Brawer et al. 1986, Convery et al. 1990). Preantral follicles were defined as follicles without any antral cavity and with two or more layers of granulosa cells. Antral follicles were counted when the nucleus of the oocyte was visible 
(Lara et al. 2000). Follicles presenting normal theca and granulosa cell layers, but devoid of an oocyte, were considered healthy antral follicles due to the limitations of histology that does not always allow its visualization. In this study, the term 'healthy' represented the sum of follicles (preantral, antral, and other healthy follicles) presenting normal granulosa and theca cell layers, not showing deformation or pyknotic cells. Atretic follicles were defined as those follicles exhibiting deformation (shrinkage or collapsing) or lacking the oocyte (Brawer $e$ al . 1986, Lara et al. 2000) or presenting granulosa cells with pyknotic nuclei (Brawer et al. 1986). A cystic follicle was considered to be a large fluid-filled cyst with an attenuated granulosa cell layer and thickened theca interna cell layer (Brawer et al. 1986, Lara et al. 2000, Manneras et al. 2007). Cells facing the cyst were flat and epithelioid, and the cyst fluid invariably contained macrophages (Manneras et al. 2007). Type III follicles were defined as large follicular structures (Brawer et al. 1986, Desjardins \& Brawer 1989) and distinguished from large secondary follicles by virtue of the fact that they did not contain ova. The granulosa membrane was thick and often plicate.

\section{Statistical analysis}

Results are expressed as mean \pm s.E.M. Comparison between groups was evaluated by the Student's $t$-test, or when multiple comparisons were to be made, a GLM-ANOVA was performed. Homeostasis model assessment for IR (HOMAIR) was calculated by the following formula: (fasted glucose $(\mathrm{mmol} / \mathrm{l}) \times$ fasted insulin $(\mathrm{ng} / \mathrm{ml}) / 22 \cdot 5)$ for all animals, as previously reported (Andrikopoulos et al. 2008). The area under the curve (AUC) was calculated using the trapezoidal rule. Data were considered to be significant at $P \leq 0 \cdot 05$.

\section{Results}

Body weight, plasma glucose and insulin levels

Female NZO and C57BL/6J control mice were studied at three ages and the basic metabolic data are shown in Table 1. As expected, both strains of mice increased their body weights
(BW) with aging, with the NZO being heavier at all three time-points compared with control mice. Plasma glucose levels were higher in NZO at the young and adult but not the aged time-point compared with C57BL/6J. Plasma insulin levels were higher at all ages in NZO compared with C57BL/ $6 \mathrm{~J}$, reflective of their insulin-resistant state. Consequently, HOMA-IR, an index of IR, was higher in the NZO compared with C57BL/6J at all ages (Table 1).

\section{Insulin tolerance test}

Figure 1A shows plasma glucose levels during an insulin tolerance test and the data are depicted as AUC in Fig. 1B. NZO mice were clearly insulin resistant compared with C57BL/6J mice at all three ages tested, as indicated by greater AUC for glucose following an insulin bolus.

\section{Breeding performance}

Table 2 shows breeding performance data of four pairs of $\mathrm{NZO}$ and C57BL/6J mice. It is clear that for all parameters tested, including number of litters, number of pups born, number of pups weaned, and therefore survival rate to weaning, the NZO displayed significantly lower numbers compared with the C57BL/6J strain. This is a clear representation of the poor breeding performance of the NZO strain.

\section{Plasma testosterone, $\mathrm{LH}$ and $\mathrm{E}_{2}$ levels}

Plasma testosterone levels were not different between NZO and C57BL/6J mice at the young and adult stages (Table 3). However, at the aged stage, there was a significant difference in plasma testosterone with significantly lower levels in NZO mice than in the C57BL/6J control. With age, plasma testosterone levels fell in the NZO female mice, while they increased in the C57BL/6J (Table 3).

Plasma LH levels were significantly reduced in young NZO compared with young C57BL/6J mice (Table 3). Age did not affect plasma LH levels in the C57BL/6J mice, while there was a significant increase in the NZO between young and adult/aged mice (Table 3).

Table 1 Body weight, 6-h fasted plasma glucose, plasma insulin and insulin resistance index (HOMA-IR) in female New Zealand obese and C57BL/6J mice $(n=5-12)$. Values presented as mean \pm S.E.M.

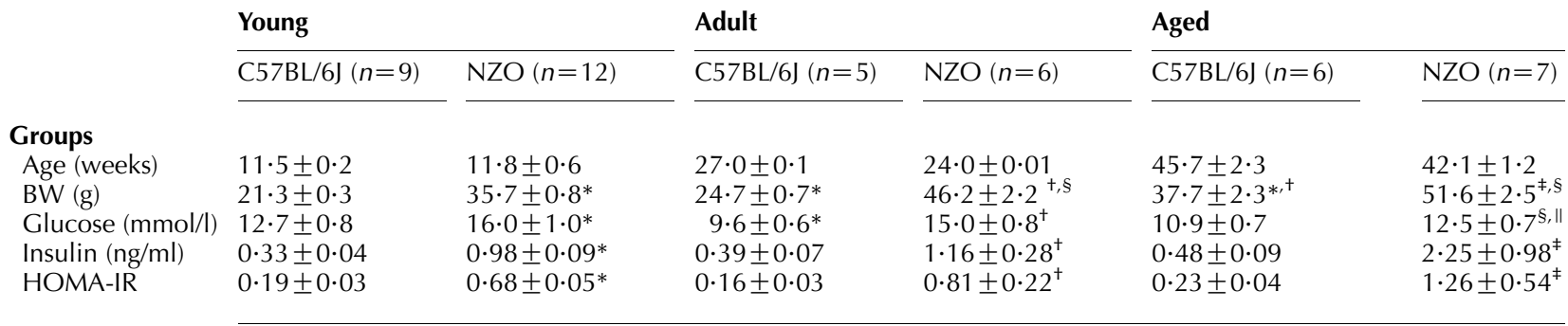

${ }^{*} P<0.05$ versus young C57BL/6); ${ }^{+} P<0 \cdot 05$ versus adult C57BL/6); ${ }^{\ddagger} P<0 \cdot 05$ versus aged $\mathrm{C} 57 \mathrm{BL} / 6 \mathrm{~J} ;{ }^{\circledR} P<0 \cdot 05$ versus young NZO; $P<0 \cdot 05$ versus adult NZO. 

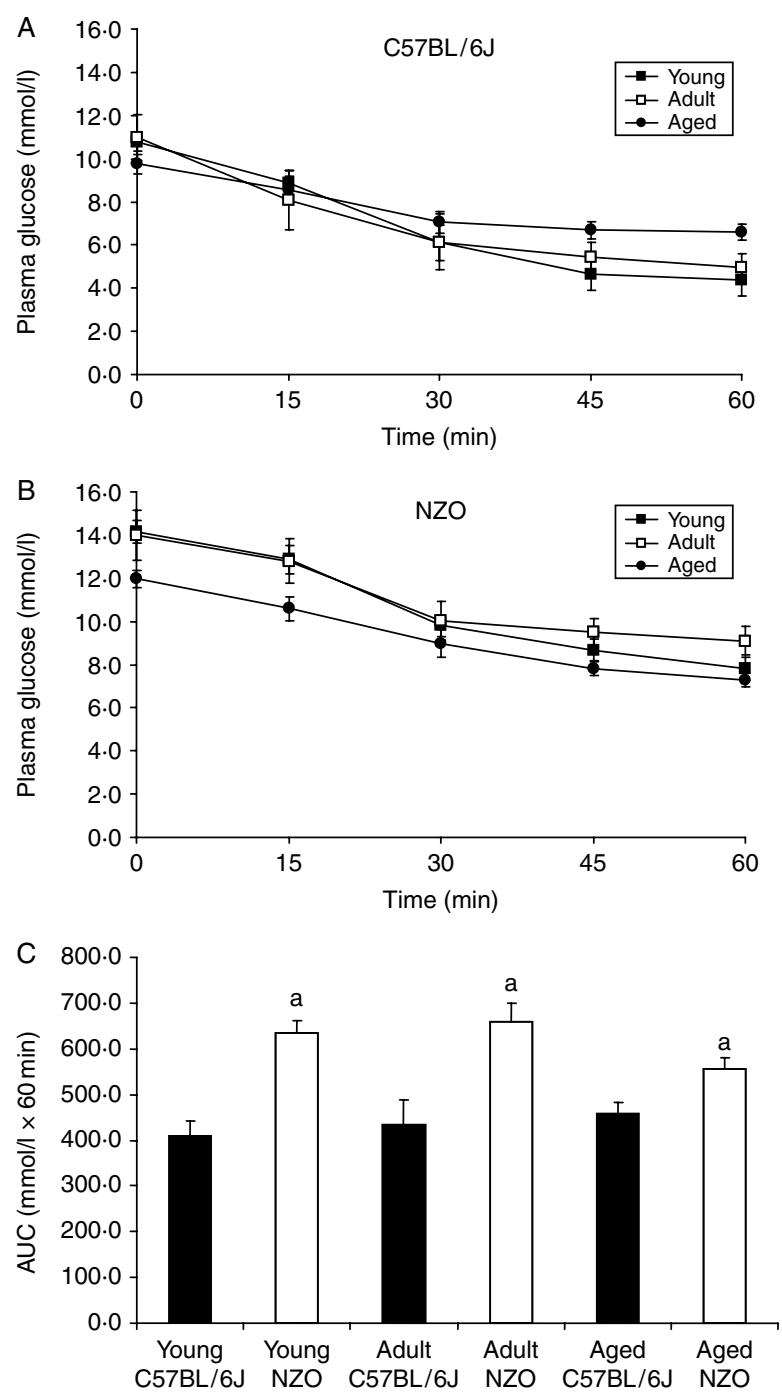

Figure 1 (A) Plasma glucose levels during an insulin tolerance test $(1 \mathrm{lU} / \mathrm{kg})$ in female C56BL/6J and NZO mice at the young, adult and aged stages as defined in Materials and Methods. (B) Area under the curve $(A \cup C)$ of glucose of the insulin tolerance test. Values are presented as mean \pm S.E.M. $(n=6-8) .{ }^{\text {a }} P<0 \cdot 05$ versus $\mathrm{C} 56 \mathrm{BL} / 6 \mathrm{~J}$.

In contrast, plasma $\mathrm{E}_{2}$ levels were higher in young $\mathrm{NZO}$ compared with young C57BL/6J mice, while there was no difference at any other time-point (Table 3). There was a significant increase in plasma $\mathrm{E}_{2}$ levels in young compared with aged NZO mice, while this parameter was actually lower in young compared with aged C57BL/6J mice (Table 3).

\section{Ovarian histology}

Histological analysis was performed on ovaries from NZO and $\mathrm{C} 57 \mathrm{BL} / 6 \mathrm{~J}$ mice at the three different ages, and the images are presented in Fig. 2. Strikingly, the NZO mice had larger ovaries particularly at the young stage with the presence of

antral follicles compared with young C57BL/6J. Healthy follicles were more prominent in C57BL/6J ovaries, with CL evident in both strains in all three ages tested. Quantification of these images was performed, and the data are presented in Figs 3 and 4.

Assessment of ovarian size confirmed the initial histological observations that NZO mice at all three ages had larger ovaries compared with control C57BL/6J mice (Fig. 3A). This difference persisted in the young NZO compared with young $\mathrm{C} 57 \mathrm{BL} / 6 \mathrm{~J}$ mice even when corrected for $\mathrm{BW}$ (35 102 \pm 5422 vs $25531 \pm 9360, n=8-9, P=0 \cdot 019$ ). Interestingly, the number of CL was significantly lower in young and adult NZO compared with C57BL/6J mice, indicative of a decreased rate of ovulation (Fig. 3B). There was no difference in CL in aged mice between the two strains. There was a significant positive correlation between fasted plasma insulin levels and ovarian size (Fig. 3C, $r=0 \cdot 40$, $P=0.013)$ when both $\mathrm{C} 57 \mathrm{BL} / 6 \mathrm{~J}$ and NZO mice were considered together.

The total number of follicles was higher in young and aged NZO compared with C57BL/6J mice (Fig. 4A). The number of primordial (immature) follicles was higher in the young NZO compared with young C57BL/6J mice (Fig. 4B), which may account for the higher total number at this age (Fig. 4A). There was a decrease in primordial follicle number in both strains such that the aged animals had significantly lower numbers compared with young mice (Fig. 4B). When the number of healthy and atretic (unhealthy) follicles was calculated, it was clear that young NZO mice had a higher number of healthy follicles (Fig. 4C) and also a higher number of atretic follicles (Fig. 4D) compared with C57BL/6J mice. The number of healthy follicles declined with age in NZO mice, while there was a significant decrease only in the aged C57BL/6J mice (Fig. 4C). Interestingly, there was no difference in atretic follicle numbers in adult and aged $\mathrm{NZO}$ and C57BL/6J mice (Fig. 4D). When the number of healthy and atretic follicles was expressed as a percentage, it is clear that young NZO mice had a higher percentage of atretic follicles compared with C57BL/6J mice (Fig. 4E). There was no difference in the percentage of atretic follicles at the two older ages. Of note, there was a significant increase in the percent of atretic follicles in aged C57BL/6J mice compared with younger mice from the same strain (Fig. 4E).

Table 2 Breeding outcomes of C57BL/6J and New Zealand obese mice. Values presented as means \pm s.E.M.

Number of litters

Number of pups born

Number of pups weaned

Survival rate $(\%)$

$* P<0 \cdot 05$ versus $\mathrm{C} 57 \mathrm{BL} / 6]$. 
Table 3 Reproductive hormonal levels following a 6-h fast in female New Zealand obese and C57BL/6J mice $(n=5-12)$. Values presented as mean \pm S.E.M.

\begin{tabular}{|c|c|c|c|c|c|c|}
\hline & \multicolumn{2}{|l|}{ Young } & \multicolumn{2}{|l|}{ Adult } & \multicolumn{2}{|l|}{ Aged } \\
\hline & $\mathrm{C} 57 \mathrm{BL} / 6 \mathrm{~J}(n=9)$ & $\mathrm{NZO}(n=12)$ & C57BL6J $(n=5)$ & $\mathrm{NZO}(n=6)$ & $\mathrm{C} 57 \mathrm{BL} / 6 \mathrm{~J}(n=6)$ & $\mathrm{NZO}(n=7)$ \\
\hline \multicolumn{7}{|l|}{ Groups } \\
\hline $\mathrm{LH}(\mathrm{ng} / \mathrm{ml})$ & $0 \cdot 21 \pm 0 \cdot 04$ & $0 \cdot 09 \pm 0 \cdot 01^{*}$ & $0 \cdot 23 \pm 0.47$ & $0 \cdot 27 \pm 0 \cdot 05^{\S}$ & $0 \cdot 48 \pm 0 \cdot 24$ & $0 \cdot 31 \pm 0.07^{\S}$ \\
\hline Estradiol (pg/ml) & $2 \cdot 7 \pm 0 \cdot 1$ & $5 \cdot 1 \pm 1 \cdot 4^{*}$ & $3 \cdot 3 \pm 1 \cdot 3$ & $3 \cdot 2 \pm 1 \cdot 0^{\S}$ & $3 \cdot 6 \pm 1 \cdot 0^{*}$ & $3 \cdot 8 \pm 1 \cdot 3^{\S}$ \\
\hline
\end{tabular}

${ }^{*} P<0 \cdot 05$ versus young $\mathrm{C} 57 \mathrm{BL} / 6 \mathrm{j} ;{ }^{+} P<0 \cdot 05$ versus adult $\mathrm{C} 57 \mathrm{BL} / 6 \mathrm{~J} ;{ }^{\ddagger} P<0 \cdot 05$ versus aged $\mathrm{C} 57 \mathrm{BL} / 6 \mathrm{~J} ;{ }^{\$} P<0 \cdot 05$ versus young NZO.

\section{Discussion}

Infertility can be associated with features of the metabolic syndrome, obesity, IR, and polycystic and enlarged ovaries. We assessed the cause of the poor breeding performance of the NZO mouse that is characterized by obesity, hyperinsulinemia, glucose intolerance, and liver and muscle IR (Veroni et al. 1991). Furthermore, these mice present with additional defects that are characteristic of the human metabolic syndrome, including dyslipidemia, hypercholesterolemia, and hypertension (Ortlepp et al. 2000). In the present study, we confirmed the obese and insulin-resistant state of the NZO mice by measuring BW and performing insulin tolerance tests. We also confirmed the poor breeding performance of the NZO strain compared with the C57BL/6J. The NZO mouse is an inbred polygenic model of obesity and therefore does not have an appropriate control strain (Andrikopoulos et al. 2000a). We have used the C57BL/6J strain for this study as it is generally used as a control strain for many metabolic studies; it is the preferred strain for the generation of genetically modified models (Wong et al. 2010) and, according to the JAX website, is considered a good breeder (http://jaxmice.jax.org/strain/ 000664.html). The metabolic features and the well-known poor reproductive rate of the NZO mouse (Bielschowsky \& Bielschowsky 1956, Koza et al. 2004) provided us with reason
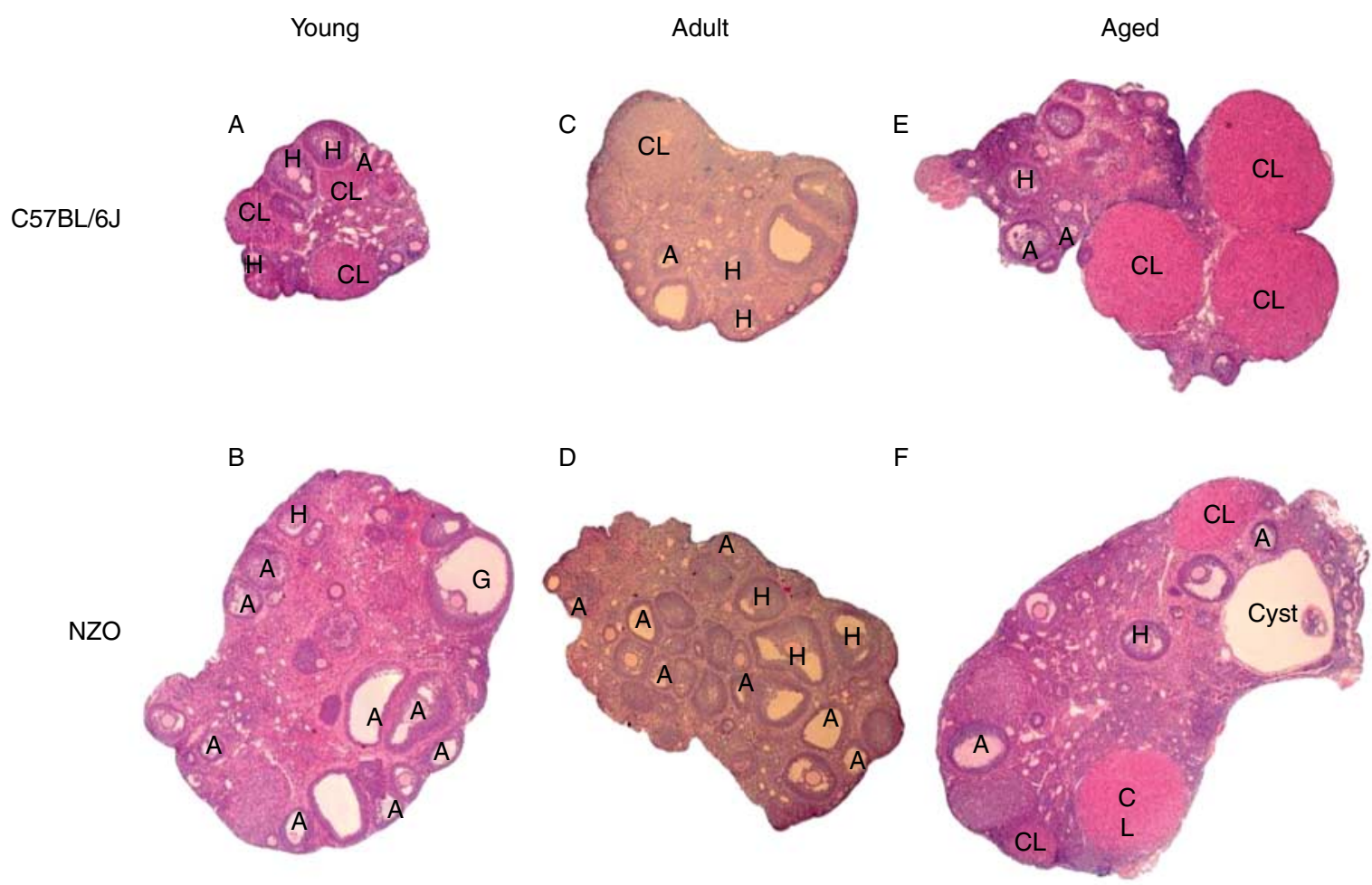

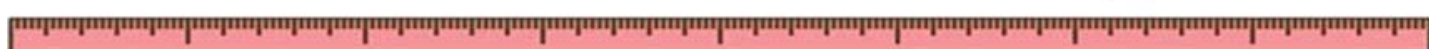

Figure 2 Histological assessment of ovarian structure (125× magnification) in young C57BL/6) and NZO mice (A and B); adult C57BL/6J and NZO mice (C and D); and aged C57BL/6J and NZO mice (E and F). A, atretic follicles; CL, corpora lutea; G, graafian; $\mathrm{H}$, healthy follicles. 


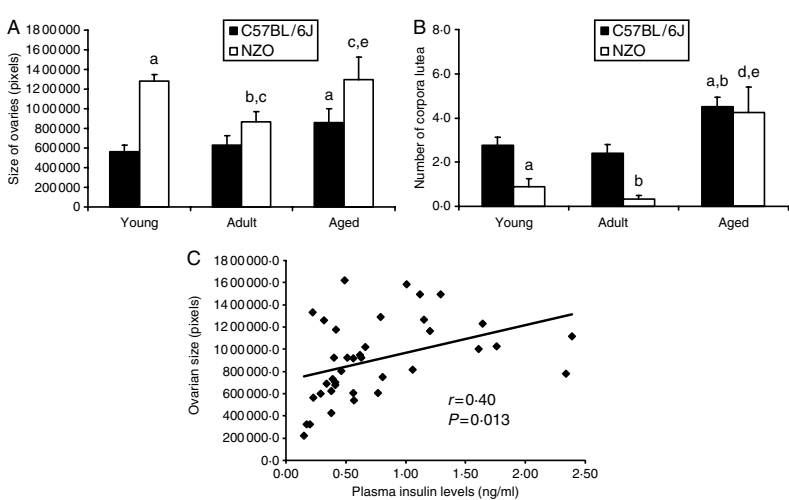

Figure 3 (A) Size of ovaries; (B) number of corpora lutea; (C) correlation between fasted plasma insulin and ovarian size in $\mathrm{C} 57 \mathrm{BL} / 6 \mathrm{~J}$ and NZO mice. Values are presented as mean \pm S.E.M. $(n=6-8) ; P<0.05 ;{ }^{\text {a }} P<0.05$ versus young $\left.\mathrm{C} 56 \mathrm{BL} / 6\right) ;{ }^{\mathrm{b}} P<0.05$ versus adult $\mathrm{C} 56 \mathrm{BL} / 6 \mathrm{~J}$; ${ }^{\mathrm{C}} P<0 \cdot 05$ versus aged $\mathrm{C} 56 \mathrm{BL} / 6 \mathrm{~J}$; ${ }^{\mathrm{d}} P<0 \cdot 05$ versus young NZO; ${ }^{e} P<0 \cdot 05$ versus adult $\mathrm{NZO}$.

to study it further. Studying NZO and C57BL/6J mice at different ages allowed us to reach some novel conclusions, specifically, regarding changes in ovarian size, the number of follicles (healthy and atretic) and CL, and reproductive hormonal levels as discussed below.

We showed that the NZO mice had an increased ovarian size, particularly at the young age. This is a well-known morphological characteristic of women with infertility associated with polycystic ovaries and has been shown to correlate with serum insulin and IR markers and with ovarian blood flow (Herter et al. 1996, Carmina et al. 2005). We also found a significant positive correlation between plasma insulin levels and ovarian size in the mice studied in our experiments (Fig. 3C). While it is certainly plausible, whether insulin is a significant contributor to increased ovarian size has not been formally tested. The number of follicles was also higher in the young NZO mice compared with controls and this is also a feature of polycystic ovaries in humans associated with IR and serum testosterone levels (Hahn et al. 2006, Sikka et al. 2007). This was most likely contributed to by an increase in the number of primordial follicles in the young NZO mice. An increase in primordial follicular number is a feature of polycystic ovaries and has been recently suggested to be due to a structural change in the ovarian cortex preventing maturation (Woodruff \& Shea 2011). Interestingly, while the number of healthy follicles was also increased, the number of atretic follicles was increased to a greater degree such that the ratio of atretic to healthy follicles was higher in the young $\mathrm{NZO}$ compared with control mice. The degree of atresia varied in NZO mice, with some follicles showing nuclear pyknosis in only a few periantral cells, whereas others exhibited massive degeneration of the central granulosa cell layers into the antrum, and degenerate cells containing pyknotic nuclei scattered throughout the granulosa membrane. Dying apoptotic cells in atretic follicles can secrete soluble factors that recruit macrophages (Ravichandran 2003) which appear in the follicular fluid during atresia. The macrophages can then cross and disrupt the basement membrane separating the vascular granulosa membrane from the theca cell layer (Manneras et al. 2007), as we observed in our study. Similar changes have been shown in other animal models of induced polycystic ovaries, with ovaries with atretic antral follicles, a thickened theca inner cell layer, a diminished granulosa cell compartment, and few fresh CL (Anderson \& Lee 1997, Lara et al. 2000, Baravalle et al. 2006, Manneras et al. 2007).

The number of CL was decreased in young and adult NZO mice compared with controls, suggesting reduced ovulatory rate and explaining the poor breeding performance of this strain (Bielschowsky \& Bielschowsky 1956). It has previously been reported that NZO mice present fewer litters than control mice and regular estrous cycle is seen only occasionally in these animals (Bielschowsky \& Bielschowsky 1956). Metabolic abnormalities of NZO mice were first reported by Bielschowsky (1953) and the poor breeding was shown 1 year later (Runner \& Gates 1954). This is supported by Lara et al. 2000, who found a significantly decreased number and size of the CL in rats with steroid-induced PCOS compared with controls. Interestingly, in the aged mice, there was no difference in the number of CL, which likely reflects the prolonged time required for these structures to be sequestered in rodents (Manneras et al. 2007).

Of interest is that testosterone levels were not different between NZO and C57BL/6J mice at the young and adult stages. Other models with polycystic ovaries also display

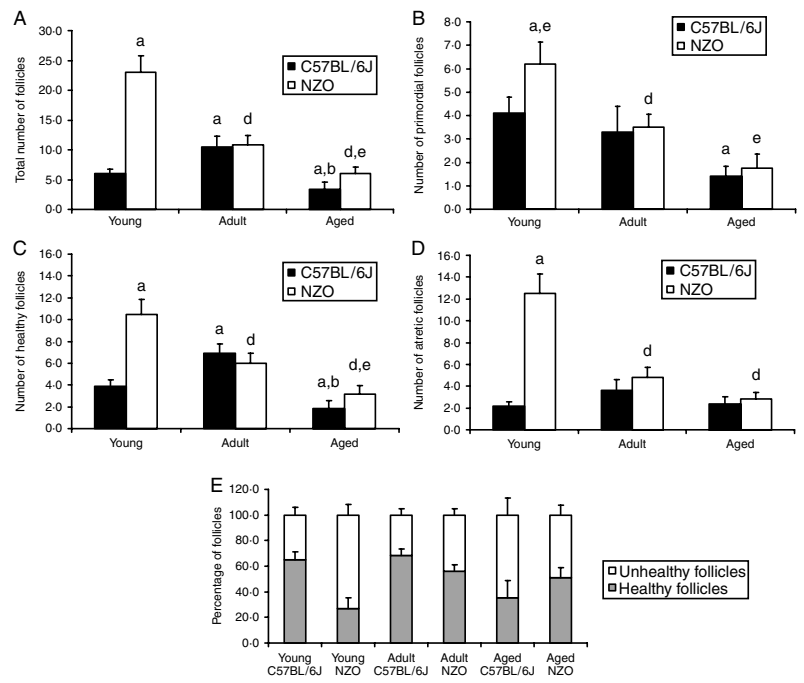

Figure 4 (A) Total number of follicles; (B) number of primordial follicles; (C) number of healthy follicles; (D) number of atretic follicles and (E) percentage of healthy and unhealthy follicles in female $\mathrm{C} 57 \mathrm{BL} / 6 \mathrm{~J}$ and NZO mice. Values are presented as mean \pm S.E.M. $(n=6-8) .{ }^{\text {a }} P<0.05$ versus young $C 57 ;{ }^{b} P<0.05$ versus adult $\mathrm{C} 57 ;{ }^{\mathrm{C}} P<0.05$ versus aged $\mathrm{C} 57 ;{ }^{\mathrm{d}} P<0.05$ versus young NZO; ${ }^{\mathrm{e}} P<0.05$ versus adult NZO. 
normal testosterone levels (Manneras et al. 2007) and hyperandrogenemia is not always seen in patients with PCOS (Rotterdam 2004). Furthermore, LH levels were lower in young NZO compared with C57BL/6J mice but no differences were seen at the older ages tested. LH levels actually increased with advancing age in the obese and insulin-resistant NZO mice, in agreement with previous studies in women with PCOS (Piouka et al. 2009), including in adolescents with this syndrome (Eagleson et al. 2000). However, we are aware that the pulsatile nature of $\mathrm{LH}$ release can make LH levels measured at a single time-point difficult to interpret. Similarly, we did observe a significant increase in plasma testosterone levels in aged C57BL/6J mice compared with all other groups. The reason for this is not clear. While a number of studies have assessed testosterone levels at different ages of male C57BL/6J mice (Shapiro et al. 1989, Ewart-Toland et al. 1999, Krishnamurthy et al. 2001, Brouillette et al. 2005), such information is not available for female mice. It is important to state that the 2003 Rotterdam consensus criteria state that PCOS can be present and diagnosed without evidence of higher testosterone or $\mathrm{LH}$ levels (Rotterdam 2004). In fact, the ovarian dysfunction and PCOS, previously excluded by NIH definition, without hyperandrogenism phenotype are typically characterized with lower LH levels compared with control (Kauffman et al. 2007). The characteristics displayed by the NZO mouse (normal androgen levels, increased ovarian size, and number of follicles) represent perhaps $10 \%$ of PCOS cases in women. This is evidence of the heterogeneity of the phenotype of PCOS.

Finally, the higher $\mathrm{E}_{2}$ levels displayed by the young NZO compared with young C57BL/6J mice may be the cause of the decreased LH levels in the obese group, as seen in PCOS (Holte et al. 1994, Morales et al. 1996. Arroyo et al. 1997, Taylor et al. 1997, Pagan et al. 2006). This increase in $\mathrm{E}_{2}$ may, in fact, reflect a greater number of follicles in the young NZO mouse, as depicted in Fig. 4C. Interestingly, $\mathrm{E}_{2}$ levels decreased with advancing age in the NZO mice only as expected (Lu et al. 1979, Nelson et al. 1995, Frick 2009), since ovarian hormonal levels diminish as menopause approaches in humans, and reproductive senescence in rodents is similar to menopause in several critical respects, including similar alterations in pulsatile LH release and the LH surge, variability of cycle length prior to acyclicity, and ultimate cessation of hormone cycling (LeFevre \& McClintock 1988, Nelson et al. 1995, Frick 2009).

A limitation of the current study, which is important to note, is that all measurements reported here including circulating hormones and ovarian structure experiments were not matched for the estrous cycle stage. Despite much effort using vaginal swabs, it proved difficult to identify the different stages of the estrous cycle in these mice. It has been reported that the estrous cycle using vaginal swabs is not as discernible in mice as it is in rats (Caligioni 2009). Furthermore, it has been reported that stress can have a significant impact on ovarian hormone levels in rodents, leading to higher $\mathrm{E}_{2}$ levels (Garland et al. 1987, MacNiven et al. 1992, Bowman \& Miller 1996, Shors et al. 1999). We assessed hormonal levels and harvested ovaries for histological assessment 1 week following the vaginal swabs to ensure that the animals had enough time to recover from the stress of the handling to perform this task. We were able to show that NZO mice presented neither hyperandrogenemia nor primary ovarian insufficiency (evidenced by the absence of low $\mathrm{E}_{2}$ levels). In addition, ovarian structure data obtained on the same day as blood sample collections confirm functional cycle disturbances in these NZO mice.

In conclusion, this study describes ovarian morphological characteristics in the obese and insulin-resistant NZO mouse that may be well associated with the pathophysiological mechanism involved in the recognized poor reproductive performance of this strain of mice. Therefore, the NZO mouse is a suitable animal model to assess the adverse effects of obesity and IR on ovarian structure and function.

\section{Declaration of interest}

The authors declare that there is no conflict of interest that could be perceived as prejudicing the impartiality of the research reported.

\section{Funding}

S R B is a grant recipient from Coordenação de Aperfeiçoamento de Pessoal de Nivel Superior, CAPES, Brazil. S A was a National Health and Medical Research Council of Australia Career Development Award Recipient. This study was supported by the Sir Edward Dunlop Medical Research Foundation.

\section{Acknowledgements}

We thank Mr Christian Rantzau for performing the insulin RIA, Associate Professor Mark Hedger from the Monash Medical Centre for performing the testosterone, $\mathrm{LH}$ and $\mathrm{E}_{2}$ RIA and Dr Ann Drummond from the Prince Henry's Institute who helped with the histological assessment.

\section{References}

Abbott DH, Dumesic DA, Eisner JR, Colman RJ \& Kemnitz JW 1998 Insights into the development of polycystic ovary syndrome (PCOS) from studies of prenatally androgenized female rhesus monkeys. Trends in Endocrinology and Metabolism 9 62-67. (doi:10.1016/S10432760(98)00019-8)

Abbott DH, Barnett DK, Bruns CM \& Dumesic DA 2005 Androgen excess fetal programming of female reproduction: a developmental aetiology for polycystic ovary syndrome? Human Reproduction Update 11 357-374. (doi:10.1093/humupd/dmi013)

Abbott DH, Zhou R, Bird IM, Dumesic DA \& Conley AJ 2008 Fetal programming of adrenal androgen excess: lessons from a nonhuman primate model of polycystic ovary syndrome. Endocrine Development 13 145-158. (doi:10.1159/000134831)

Anderson E \& Lee GY 1997 The polycystic ovarian (PCO) condition: apoptosis and epithelialization of the ovarian antral follicles are aspects of cystogenesis in the dehydroepiandrosterone (DHEA)-treated rat model. Tissue \& Cell 29 171-189. (doi:10.1016/S0040-8166(97)80017-1) 
Andrikopoulos S, Thorburn AW \& Proietto J 2000a The New Zealand obese mouse: a polygenic model of type 2 diabetes. In Animal Models of Diabetes. A Primer, pp 171-183. Eds AAF Sima \& E Shafrir. Amsterdam: Harwood Academic Publishers.

Andrikopoulos S, Verchere CB, Terauchi Y, Kadowaki T \& Kahn SE $2000 b$ Beta-cell glucokinase deficiency and hyperglycemia are associated with reduced islet amyloid deposition in a mouse model of type 2 diabetes. Diabetes 49 2056-2062. (doi:10.2337/diabetes.49.12.2056)

Andrikopoulos S, Blair AR, Deluca N, Fam BC \& Proietto J 2008 Evaluating the glucose tolerance test in mice. American Journal of Physiology. Endocrinology and Metabolism 295 E1323-E1332. (doi:10.1152/ajpendo. 90617.2008)

Arroyo A, Laughlin GA, Morales AJ \& Yen SS 1997 Inappropriate gonadotropin secretion in polycystic ovary syndrome: influence of adiposity. Journal of Clinical Endocrinology and Metabolism 82 3728-3733. (doi:10.1210/jc.82.11.3728)

Asuncion M, Calvo RM, San Millan JL, Sancho J, Avila S \& EscobarMorreale HF 2000 A prospective study of the prevalence of the polycystic ovary syndrome in unselected Caucasian women from Spain. Journal of Clinical Endocrinology and Metabolism 85 2434-2438. (doi:10.1210/jc.85.7. 2434)

Azziz R, Woods KS, Reyna R, Key TJ, Knochenhauer ES \& Yildiz BO 2004 The prevalence and features of the polycystic ovary syndrome in an unselected population. Journal of Clinical Endocrinology and Metabolism $\mathbf{8 9}$ 2745-2749. (doi:10.1210/jc.2003-032046)

Baravalle C, Salvetti NR, Mira GA, Pezzone N \& Ortega HH 2006 Microscopic characterization of follicular structures in letrozole-induced polycystic ovarian syndrome in the rat. Archives of Medical Research 37 830-839. (doi:10.1016/j.arcmed.2006.04.006)

Barber TM, McCarthy MI, Wass JA \& Franks S 2006 Obesity and polycystic ovary syndrome. Clinical Endocrinology 65 137-145. (doi:10.1111/j.13652265.2006.02587.x)

Barnes RB, Rosenfield RL, Ehrmann DA, Cara JF, Cuttler L, Levitsky LL \& Rosenthal IM 1994 Ovarian hyperandrogynism as a result of congenital adrenal virilizing disorders: evidence for perinatal masculinization of neuroendocrine function in women. Journal of Clinical Endocrinology and Metabolism 79 1328-1333. (doi:10.1210/jc.79.5.1328)

Beloosesky R, Gold R, Almog B, Sasson R, Dantes A, Land-Bracha A, Hirsh L, Itskovitz-Eldor J, Lessing JB, Homburg R et al. 2004 Induction of polycystic ovary by testosterone in immature female rats: modulation of apoptosis and attenuation of glucose/insulin ratio. International Journal of Molecular Medicine 14 207-215.

Bielschowsky F 1953 The role of ovarian secretions in the pathogenesis of chemically induced cancers. Acta Physiologica Latino Americana 3 57-59.

Bielschowsky F \& Bielschowsky M 1956 The New Zealand strain of obese mice; their response to stilboestrol and to insulin. Australian Journal of Experimental Biology and Medical Science 34 181-198. (doi:10.1038/icb. 1956.22)

Bowman BM \& Miller SC 1996 Elevated progesterone during pseudopregnancy may prevent bone loss associated with low estrogen. Journal of Bone and Mineral Research 11 15-21. (doi:10.1002/jbmr.5650110104)

Brawer JR, Munoz M \& Farookhi R 1986 Development of the polycystic ovarian condition (PCO) in the estradiol valerate-treated rat. Biology of Reproduction 35 647-655. (doi:10.1095/biolreprod35.3.647)

Brouillette J, Rivard K, Lizotte E \& Fiset C 2005 Sex and strain differences in adult mouse cardiac repolarization: importance of androgens. Cardiovascular Research 65 148-157. (doi:10.1016/j.cardiores.2004.09.012)

Caligioni CS 2009 Assessing reproductive status/stages in mice. Current Protocols in Neuroscience Appendox 4 Appendix 4I.

Carmina E, Orio F, Palomba S, Longo RA, Lombardi G \& Lobo RA 2005 Ovarian size and blood flow in women with polycystic ovary syndrome and their correlations with endocrine parameters. Fertility and Sterility $\mathbf{8 4}$ 413-419. (doi:10.1016/j.fertnstert.2004.12.061)

Convery M, McCarthy GF \& Brawer JR 1990 Remission of the polycystic ovarian condition (PCO) in the rat following hemiovariectomy. Anatomical Record 226 328-336. (doi:10.1002/ar.1092260309)
Crosignani PG \& Nicolosi AE 2001 Polycystic ovarian disease: heritability and heterogeneity. Human Reproduction Update 7 3-7. (doi:10.1093/humupd/ 7.1.3)

Desjardins GC \& Brawer JR 1989 Development and maintenance of a polycystic condition in ovaries autotransplanted under the kidney capsule. Anatomical Record 225 118-123. (doi:10.1002/ar.1092250206)

Dunaif A 1997 Insulin resistance and the polycystic ovary syndrome: mechanism and implications for pathogenesis. Endocrine Reviews 18 774-800. (doi:10.1210/er.18.6.774)

Eagleson CA, Gingrich MB, Pastor CL, Arora TK, Burt CM, Evans WS \& Marshall JC 2000 Polycystic ovarian syndrome: evidence that flutamide restores sensitivity of the gonadotropin-releasing hormone pulse generator to inhibition by estradiol and progesterone. Journal of Clinical Endocrinology and Metabolism 85 4047-4052. (doi:10.1210/jc.85.11.4047)

Ehrmann DA 2005 Polycystic ovary syndrome. New England Journal of Medicine 352 1223-1236. (doi:10.1056/NEJMra041536)

Ewart-Toland A, Mounzih K, Qiu J \& Chehab FF 1999 Effect of the genetic background on the reproduction of leptin-deficient obese mice. Endocrinology 140 732-738. (doi:10.1210/en.140.2.732)

Fam BC, Morris MJ, Hansen MJ, Kebede M, Andrikopoulos S, Proietto J \& Thorburn AW 2007 Modulation of central leptin sensitivity and energy balance in a rat model of diet-induced obesity. Diabetes, Obesity and Metabolism 9 840-852. (doi:10.1111/j.1463-1326.2006.00653.x)

Franks S, Mason H \& Willis D 2000 Follicular dynamics in the polycystic ovary syndrome. Molecular and Cellular Endocrinology 163 49-52. (doi:10. 1016/S0303-7207(99)00239-7)

Franks S, McCarthy MI \& Hardy K 2006 Development of polycystic ovary syndrome: involvement of genetic and environmental factors. International Journal of Andrology 29 278-285 discussion 286-290. (doi:10.1111/j.13652605.2005.00623.x)

Frick KM 2009 Estrogens and age-related memory decline in rodents: what have we learned and where do we go from here? Hormones and Behavior 55 2-23. (doi:10.1016/j.yhbeh.2008.08.015)

Garland HO, Atherton JC, Baylis C, Morgan MR \& Milne CM 1987 Hormone profiles for progesterone, oestradiol, prolactin, plasma renin activity, aldosterone and corticosterone during pregnancy and pseudopregnancy in two strains of rat: correlation with renal studies. Journal of Endocrinology 113 435-444. (doi:10.1677/joe.0.1130435)

Hahn S, Bering van Halteren W, Roesler S, Schmidt M, Kimmig R, Tan S, Mann K \& Janssen OE 2006 The combination of increased ovarian volume and follicle number is associated with more severe hyperandrogenism in German women with polycystic ovary syndrome. Experimental and Clinical Endocrinology and Diabetes 114 175-181. (doi:10.1055/s-2006-924063)

Herter LD, Magalhaes JA \& Spritzer PM 1996 Relevance of the determination of ovarian volume in adolescent girls with menstrual disorders. Journal of Clinical Ultrasound 24 243-248. (doi:10.1002/ (SICI) 1097-0096(199606)24:5 <243::AID-JCU3 > 3.0.CO;2-E)

Holte J, Bergh T, Gennarelli G \& Wide L 1994 The independent effects of polycystic ovary syndrome and obesity on serum concentrations of gonadotrophins and sex steroids in premenopausal women. Clinical Endocrinology 41 473-481. (doi:10.1111/j.1365-2265.1994.tb02578.x)

Kafali H, Iriadam M, Ozardali I \& Demir N 2004 Letrozole-induced polycystic ovaries in the rat: a new model for cystic ovarian disease. Archives of Medical Research 35 103-108. (doi:10.1016/j.arcmed.2003.10.005)

Kauffman AS, Gottsch ML, Roa J, Byquist AC, Crown A, Clifton DK, Hoffman GE, Steiner RA \& Tena-Sempere M 2007 Sexual differentiation of Kiss1 gene expression in the brain of the rat. Endocrinology 148 1774-1783. (doi:10.1210/en.2006-1540)

Koza RA, Flurkey K, Graunke DM, Braun C, Pan HJ, Reifsnyder PC, Kozak LP \& Leiter EH 2004 Contributions of dysregulated energy metabolism to type 2 diabetes development in NZO/H1Lt mice with polygenic obesity. Metabolism 53 799-808. (doi:10.1016/j.metabol.2003. 12.024)

Krishnamurthy H, Babu PS, Morales CR \& Sairam MR 2001 Delay in sexual maturity of the follicle-stimulating hormone receptor knockout male mouse. Biology of Reproduction 65 522-531. (doi:10.1095/biolreprod65.2.522)

Lara HE, Dissen GA, Leyton V, Paredes A, Fuenzalida H, Fiedler JL \& Ojeda SR 2000 An increased intraovarian synthesis of nerve growth factor 
and its low affinity receptor is a principal component of steroid-induced polycystic ovary in the rat. Endocrinology 141 1059-1072. (doi:10.1210/en. 141.3.1059)

Leeman L \& Acharya U 2009 The use of metformin in the management of polycystic ovary syndrome and associated anovulatory infertility: the current evidence. Journal of Obstetrics and Gynaecology 29 467-472. (doi:10.1080/01443610902829414)

LeFevre J \& McClintock MK 1988 Reproductive senescence in female rats: a longitudinal study of individual differences in estrous cycles and behavior. Biology of Reproduction 38 780-789. (doi:10.1095/biolreprod38.4.780)

Lobo RA \& Carmina E 2000 The importance of diagnosing the polycystic ovary syndrome. Annals of Internal Medicine 132 989-993.

Lu KH, Hopper BR, Vargo TM \& Yen SS 1979 Chronological changes in sex steroid, gonadotropin and prolactin secretions in aging female rats displaying different reproductive states. Biology of Reproduction 21 193-203. (doi:10.1095/biolreprod21.1.193)

MacNiven E, deCatanzaro D \& Younglai EV 1992 Chronic stress increases estrogen and other steroids in inseminated rats. Physiology and Behavior 52 159-162. (doi:10.1016/0031-9384(92)90446-9)

Manneras L, Cajander S, Holmang A, Seleskovic Z, Lystig T, Lonn M \& Stener-Victorin E 2007 A new rat model exhibiting both ovarian and metabolic characteristics of polycystic ovary syndrome. Endocrinology 148 3781-3791. (doi:10.1210/en.2007-0168)

Morales AJ, Laughlin GA, Butzow T, Maheshwari H, Baumann G \& Yen SS 1996 Insulin, somatotropic, and luteinizing hormone axes in lean and obese women with polycystic ovary syndrome: common and distinct features. Journal of Clinical Endocrinology and Metabolism 81 2854-2864. (doi:10.1210/ jc.81.8.2854)

Nelson JF, Karelus K, Bergman MD \& Felicio LS 1995 Neuroendocrine involvement in aging: evidence from studies of reproductive aging and caloric restriction. Neurobiology of Aging 16 837-843 discussion 855-836. (doi:10.1016/0197-4580(95)00072-M)

Norman RJ 2002 Hyperandrogenaemia and the ovary. Molecular and Cellular Endocrinology 191 113-119. (doi:10.1016/S0303-7207(02)00062-X)

Norman RJ, Wu R \& Stankiewicz MT 2004 4: polycystic ovary syndrome. Medical Journal of Australia 180 132-137.

Ortlepp JR, Kluge R, Giesen K, Plum L, Radke P, Hanrath P \& Joost HG 2000 A metabolic syndrome of hypertension, hyperinsulinaemia and hypercholesterolaemia in the New Zealand obese mouse. European Journal of Clinical Investigation 30 195-202. (doi:10.1046/j.1365-2362.2000.00611.x)

Pagan YL, Srouji SS, Jimenez Y, Emerson A, Gill S \& Hall JE 2006 Inverse relationship between luteinizing hormone and body mass index in polycystic ovarian syndrome: investigation of hypothalamic and pituitary contributions. Journal of Clinical Endocrinology and Metabolism 91 1309-1316. (doi:10.1210/jc.2005-2099)

Pedersen T \& Peters H 1968 Proposal for a classification of oocytes and follicles in the mouse ovary. Journal of Reproduction and Fertility 17 555-557. (doi:10.1530/jrf.0.0170555)

Piouka A, Farmakiotis D, Katsikis I, Macut D, Gerou S \& Panidis D 2009 Anti-Mullerian hormone levels reflect severity of PCOS but are negatively influenced by obesity: relationship with increased luteinizing hormone levels. American Journal of Physiology. Endocrinology and Metabolism 296 E238-E243. (doi:10.1152/ajpendo.90684.2008)

Ravichandran KS 2003 "Recruitment" signals from apoptotic cells: invitation to a quiet meal. Cell 113 817-820. (doi:10.1016/S0092-8674(03)00471-9)
Rotterdam 2004 Revised 2003 consensus on diagnostic criteria and longterm health risks related to polycystic ovary syndrome (PCOS). Human Reproduction 19 41-47. (doi:10.1093/humrep/deh098)

Runner MN \& Gates A 1954 Conception in prepuberal mice following artificially induced ovulation and mating. Nature 174 222-223. (doi:10.1038/174222b0)

Shapiro BH, Niedermeyer TM \& Babalola GO 1989 Serum androgen levels in senescent $\mathrm{Cr} 1 \mathrm{CD}-1$ (ICR)BR mice: effects of castration and testosterone treatment. Journal of Gerontology 44 B15-B19.

Shors TJ, Pickett J, Wood G \& Paczynski M 1999 Acute stress persistently enhances estrogen levels in the female rat. Stress 3 163-171. (doi:10.3109/ 10253899909001120)

Sikka P, Gainder S, Dhaliwal LK, Bagga R, Sialy R \& Sahdev S 2007 Ultrasonography of the ovaries and its correlation with clinical and endocrine parameters in infertile women with PCOS. International Journal of Fertility and Women's Medicine 52 41-47.

Spritzer PM, Poy M, Wiltgen D, Mylius LS \& Capp E 2001 Leptin concentrations in hirsute women with polycystic ovary syndrome or idiopathic hirsutism: influence on LH and relationship with hormonal, metabolic, and anthropometric measurements. Human Reproduction 16 1340-1346. (doi:10.1093/humrep/16.7.1340)

Taylor AE, McCourt B, Martin KA, Anderson EJ, Adams JM, Schoenfeld D \& Hall JE 1997 Determinants of abnormal gonadotropin secretion in clinically defined women with polycystic ovary syndrome. Journal of Clinical Endocrinology and Metabolism 82 2248-2256. (doi:10.1210/jc.82.7.2248)

Toscani M, Migliavacca R, Sisson de Castro JA \& Spritzer PM 2007 Estimation of truncal adiposity using waist circumference or the sum of trunk skinfolds: a pilot study for insulin resistance screening in hirsute patients with or without polycystic ovary syndrome. Metabolism $\mathbf{5 6}$ 992-997. (doi:10.1016/j.metabol.2007.03.006)

Veroni MC, Proietto J \& Larkins RG 1991 Evolution of insulin resistance in New Zealand obese mice. Diabetes 40 1480-1487. (doi:10.2337/diabetes. 40.11.1480)

Webber LJ, Stubbs S, Stark J, Trew GH, Margara R, Hardy K \& Franks S 2003 Formation and early development of follicles in the polycystic ovary. Lancet 362 1017-1021. (doi:10.1016/S0140-6736(03)14410-8)

Wong N, Blair AR, Morahan G \& Andrikopoulos S 2010 The deletion variant of nicotinamide nucleotide transhydrogenase (Nnt) does not affect insulin secretion or glucose tolerance. Endocrinology 151 96-102. (doi:10.1210/en.2009-0887)

Woodruff TK \& Shea LD 2011 A new hypothesis regarding ovarian follicle development: ovarian rigidity as a regulator of selection and health. Journal of Assisted Reproduction and Genetics 28 3-6. (doi:10.1007/s10815010-9478-4)

Zain MM \& Norman RJ 2008 Impact of obesity on female fertility and fertility treatment. Women's Health 4 183-194. (doi:10.2217/17455057. 4.2.183)

\section{Received in final form 15 March 2011 \\ Accepted 17 March 2011 \\ Made available online as an Accepted Preprint 23 March 2011}

